\title{
Forma arquitetônica e usos do solo: um estudo sobre seus efeitos na ocorrência de crimes
}

\author{
Architectural form and land uses: an analysis of their \\ effects on the occurrence of crimes
}

\begin{abstract}
Letícia Barause
Renato Tibiriçá de Saboya

Resumo

A

pesar de estudos empíricos já realizados sugerirem que os usos comerciais estão associados a maiores taxas de delitos, estes não levam em consideração especificidades da relação entre os usos não residenciais e sua inserção na edificação, tampouco diferenciam entre atividades de vizinhança imediata, do bairro ou da cidade como um todo. A partir disso, buscamos investigar se os estabelecimentos nãoresidenciais na área conurbada de Florianópolis (ACF) são atratores de criminalidade mesmo quando estão inseridos em edificações residenciais, bem como se há diferença nos efeitos de usos não residenciais de diferentes raios de abrangência. Extraímos uma amostra de 100 segmentos de ruas e comparamos suas características arquitetônicas e de uso do solo com as taxas de ocorrências criminais. Os resultados indicam que usos comerciais isolados na edificação estão relacionados a maiores taxas de crimes, enquanto edificações com usos comerciais e residenciais combinados se mostraram mais seguras. Ficou evidenciado também que usos não residenciais na escala da cidade são criminogênicos, o que não acontece com aqueles de bairro e de vizinhança, e que em áreas mais densas, onde hácerta verticalização, há menor taxa de crimes.
\end{abstract}

Palavras-chave: Forma arquitetônica. Usos comerciais. Comércio de bairro. Edificações mistas. Ocorrência de crimes.

\begin{abstract}
Although empirical studies strongly suggest that commercial activities are associated with higher crime rates, they do not consider whether there is any difference in the effects of isolated commercial activities, as opposed to those integrated to residential activities in the same building, and neither do they differentiate between non-residential activities in the immediate neighbourhood, in the district and city-wide. Thus, we investigated if non-residential activities in the conurbated area of Florianópolis (FCA) may be considered criminogenic even when they are integrated with residential activities in mixed buildings, and also whether different catchment areas could explain higher or lower crime rates. With that purpose, we randomly selected a sample of 100 street segments and compared their architectural and land use characteristics to crime rates. The results showed that isolated commercial use is associated with higher crime rates, whereas buildings with combined commercial and residential uses are not. The evidence also suggested that city-wide non-residential activities are criminogenic whereas those at the neighbourhood and district level do not show any association one way or another, and that higher densities, usually linked to verticalisation, were associated with lower crime rates.
\end{abstract}

${ }^{1}$ Letícia Barause 1 Universidade Federal de Santa Catarina Florianópolis - SC - Brasil

2Renato Tibiriçá de Saboya ¿Universidade Federal de Santa

Catarina

Florianópolis - SC - Brasil

Recebido em 18/11/17 Aceito em 27/02/18

Keywords: Architectural form. Commercial activities. Neighborhood retail. Mixed buildings. Crime occurrence. 


\section{Introdução}

A criminalidade das cidades brasileiras vem crescendo e deixou de ser uma característica apenas das grandes metrópoles, sendo encontrada também nas cidades de pequeno porte (INSTITUTO..., 2004; INSTITUTO..., 2009; WAISELFSZ, 2015; ENDLICH; FERNANDES, 2014). A insegurança encontrada nas ruas é reflexo de uma confluência de fatores, entre eles as condições materiais, a estrutura familiar, os vínculos com a comunidade mais próxima e a sociedade em geral, os níveis de escolaridade, as injustiças sociais e a miséria financeira (NEWBURN, 2012). A desigualdade social, alimentada pela opção por um modelo econômico capitalista, caracteriza-se como uma das principais forças motrizes da criminalidade e do consequente sentimento de insegurança social (SHECAIRA, 2004; ENDLICH; FERNANDES, 2014; D’ANTONA; DAGNINO; BUENO, 2010).

Complementarmente à consideração desses fatores mais diretamente ligados às causas da criminalidade, existem também estudos que abordam o ambiente construído como um fator de influência sobre essas ações delituosas. Esses estudiosos da chamada Criminologia Ambiental acreditam que a estrutura espacial gera oportunidades para a prática de variados tipos de delitos, apoiando-se, em maior ou menor grau, no conceito de oportunidade criminal. Neste artigo nos baseamos na Teoria da Atividade Rotineira, desenvolvida por Cohen e Felson (1979). Para Felson (2008, p. 70), o crime acontece a partir de uma convergência de três fatores, no tempo e no espaço: um indivíduo ou grupo de indivíduos com a intenção ou disposição de cometer o crime; um alvo que, por algum motivo, desperte o interesse do criminoso; e a falta de segurança adequada ou de um guardião capaz que ajude a impedir o crime.

Apesar da crença generalizada em um suposto efeito dos usos comerciais e da diversidade de usos na promoção de maior segurança nos espaços urbanos (JACOBS, 2011; ALEXANDER et al., 1977; GEHL, 2011), um exame da literatura de criminologia ambiental deixa poucas dúvidas de que a direção dos efeitos desses aspectos na ocorrência de crimes é a oposta. Perkins et al. (1993), por exemplo, encontraram que usos não residenciais são mais criminogênicos ${ }^{1}$ que usos residenciais. Entre os usos que mostraram influência negativa na segurança estão lojas,

${ }^{1}$ Considerando tanto crimes mais "leves" (venda de drogas, invasões de propriedade, ameaças, assédio, etc.) quanto crimes mais graves (roubos, incêndios, arrombamentos, roubo de veículos, homicídios, estupros, etc.). escolas e edifícios com múltiplos usos de comércios e serviços. Hillier e Sahbaz (2012) concluíram que as taxas de crimes a residências tendem a cair quando há maior proporção delas em relação a comércios e serviços no segmento de via. Portanto, a alta densidade estaria associada à menor taxa de crimes, desde que essa densidade seja residencial. Apartamentos, segundo eles, mostram-se mais seguros que casas, uma vez que o menor número de faces expostas diretamente para a rua, no nível térreo, torna a unidade habitacional menos vulnerável.

Anderson et al. (2013) apontaram que quadras mais seguras são aquelas classificadas na legislação como residenciais, considerando assaltos, agressões físicas e arrombamentos. As quadras de uso misto apresentam um meio-termo, enquanto as quadras estritamente comerciais aparecem como sendo as mais criminogênicas, com uma proporção de quase o dobro de crimes que as quadras mais seguras. Já os resultados encontrados por Sohn (2016), um dos poucos a diferenciar os tipos de usos comerciais, mostram que mercearias, restaurantes e escritórios são positivos para a melhoria da segurança no bairro, enquanto áreas com centros comerciais (shopping centers) possuíam índices de roubo a residências mais altos. No Brasil, Saboya, Banki e Santana (2016) também encontraram, em uma amostra de 122 pares de locais, que os usos comerciais estão associados à maior ocorrência de crimes (furtos, roubos e violação de domicílio), assim como a diversidade de usos. Já para os horários de funcionamento dos estabelecimentos, não foram encontradas correlações significativas, ou seja, eles não se mostraram capazes de explicar a ocorrência desses tipos de crimes.

Entretanto, esses estudos focaram-se apenas nos aspectos quantitativos das distribuições de usos, sem uma consideração mais cuidadosa da interação desses usos com a forma das edificações (BLOCK; BLOCK, 1995 ; BRANTINGHAM; BRANTINGHAM, 1995; KINNEY et al., 2008).

O princípio básico defendido por Jacobs (2011) é a ideia da vigilância natural coletiva, segundo a qual o constante movimento de pessoas em diferentes horários, gerado pela diversidade de atividades, poderia inibir os delinquentes de praticarem seus atos. Por outro lado, esses usos tendem a ter um horário de funcionamento restrito e a permanecerem fechados desde o início da noite até a manhã do dia seguinte. Em áreas com um grande número deles, boa parte do trecho de logradouro estaria privado dessa vigilância natural. 
O que argumentamos neste trabalho é que a forma como os usos não residenciais interagem com os usos residenciais, no nível do tipo arquitetônico, é determinante para seu efeito na vigilância natural e, consequentemente, na ocorrência de crimes: quando estão isolados entre si, geram pontos sem vigilância por significativos períodos; quando estão integrados na mesma edificação, podem complementar-se de maneira muito mais harmônica no que diz respeito aos horários de funcionamento e à geração de uma vigilância natural mais distribuída ao longo do dia e dos dias da semana.

De dia, os usos comerciais isolados podem atrair moradores e estranhos, e gerar vigilância natural; à noite, entretanto, permanecem fechados (em sua maioria) e fornecem áreas "cegas", que podem ser usadas por criminosos tanto para cometer crimes contra os próprios estabelecimentos comerciais, quanto para ganhar acesso às residências e para abordar pedestres nas ruas sem o risco de serem vistos.

No caso dos usos integrados às residências em uma mesma edificação, esses pontos cegos noturnos são suavizados, porque das janelas dos pavimentos superiores é possível supervisionar a rua, mesmo depois do horário comercial. Um ponto importante a ser considerado é que não é necessário que haja efetivamente essa vigilância. Basta que, do ponto de vista da percepção de um possível criminoso, ela seja razoavelmente possível, a ponto de aumentar os riscos percebidos. Isso é derivado diretamente da constatação de que um criminoso em potencial não conhece - nem tem como conhecer - todos os fatos relevantes para o crime que pretende cometer e, portanto, precisa fazer estimativas com base no que consegue apreender da situação em que se encontra. Comércios fechados à noite inspiram a confiança de que ali não há ninguém a vigiar as ruas; o mesmo não acontece com as atividades residenciais, mesmo que as janelas estejam fechadas e as luzes apagadas.

Portanto, o que propomos aqui é uma abordagem que integre aspectos da forma edificada com os usos do solo, pois é essa combinação que determina, em grande parte, a dinâmica de utilização de uma área urbana ao longo do dia e nos diferentes dias da semana. Mais especificamente, este estudo analisa se usos comerciais integrados aos usos residenciais na mesma edificação teriam os mesmos efeitos sobre a ocorrência de crimes do que quando estão isolados em edificações monofuncionais, um aspecto não contemplado por estudos anteriores. Testamos também se usos não residenciais com diferentes escalas de abrangência (local, de bairro ou de cidade) mostram-se mais ou menos associados com as ocorrências de crimes. Além disso, outros aspectos da forma arquitetônica e sua relação foram examinados com vistas a determinar se reforçam ou não os resultados obtidos pelos estudos anteriores, especialmente considerando que a grande maioria deles se refere a realidades bastante distintas da brasileira.

Esperamos, assim, contribuir para, futuramente, apoiar o lançamento de diretrizes para a redução da criminalidade por meio da arquitetura e da legislação territorial, como apoio a outras estratégias mais amplas, de tal forma que a cidade passe a ser mais segura e, consequentemente, mais agradável de se viver.

\section{Procedimentos metodológicos}

A metodologia adotada consiste em comparar diversos trechos da cidade em áreas com concentração significativa de comércios e usos diversificados, inseridos ou não em edificações residenciais, a fim de determinar se há relação significativa entre essas variáveis e as ocorrências criminais. Mais especificamente, a metodologia percorreu as etapas a seguir.

\section{Coleta e preparação de dados}

Levantamento das ocorrências criminais registradas pela Polícia Militar e pela Polícia Civil nos anos de 2014 e 2015 no Ministério Público de Santa Catarina. Os dados obtidos continham nove classificações. Dessas cinco são consideradas como variáveis dependentes do estudo em questão: roubo/assalto, furto, crimes contra a vida, violação de domicílio e drogas. Esses tipos de crimes foram definidos como sendo relevantes para esta pesquisa por serem, de alguma forma, influenciados pelo espaço (ANDERSON et al., 2013). Crimes de roubo, furto e violação de domicílio dependem diretamente do espaço físico para ocorrer, e crimes contra a vida e drogas são influenciados pelo espaço (localização, estado de conservação, visibilidade, possibilidade de fuga, entre outros aspectos), mesmo que parcialmente, e podem ser precedidos ou sucedidos pelos outros crimes citados anteriormente. Cada ocorrência criminal está georreferenciada no espaço e em alguns casos possuía também informações sobre a data e a hora do boletim de ocorrência ${ }^{2}$. Os dados coletados foram inseridos no software QGIS, um sistema de informações geográficas, para que pudessem ser

2Infelizmente, entretanto, essa informação não estava disponível em todos os registros, o que inviabilizou seu uso neste trabalho. 
espacializados na malha de Florianópolis e São José.

\section{Definição de setores censitários na porção central de Florianópolis e São José com proporção de usos comerciais e de serviços entre $20 \%$ e $70 \%$}

Com o auxílio do QGIS, elaboramos mapas com base nos dados do Cadastro Nacional de Endereços para Fins Estatísticos (CNEFE) e dos setores censitários do IBGE, a partir dos quais fizemos a seleção dos setores com quantidades similares de comércios. Dessa forma, foi possível identificar os setores censitários com incidência de $20 \%$ a $70 \%$ de estabelecimentos comerciais, de serviços e industriais em sua área (Figura 1) e, a partir deles, selecionar os trechos a serem analisados. Tal procedimento teve como objetivo evitar incluir trechos em setores monofuncionais, tanto exclusivamente residenciais quanto não residenciais, uma vez que se buscava examinar a influência dos estabelecimentos comerciais na ocorrência de crimes. Por fim, foi definido o recorte espacial da área central da Grande
Florianópolis, que possui malha urbana mais homogênea e contínua, evitando assim áreas segregadas e em tecidos urbanos muito peculiares.

\section{Sorteio de uma amostra aleatória de 100 trechos dentro dos setores definidos anteriormente}

A seleção dos trechos foi feita de forma aleatória através de uma função específica para isso no QGIS, que elegeu 100 segmentos de vias dentro dos setores de uso misto previamente selecionados (Figura 2). O número de segmentos foi definido de modo a produzir uma amostra relevante para a análise da ACF e, ao mesmo tempo, ser factível considerando o tempo e os recursos disponíveis para o estudo. Foram previamente excluídos da seleção os trechos que configuravam rodovias, pois estas não possuem interação com as edificações de seu entorno e também não permitem interação das edificações em lados opostos da via e, portanto, não representam situações urbanas típicas. Os segmentos que se encontravam em áreas sem nenhuma edificação também foram desconsiderados para a seleção da amostra.

Figura 1 - Setores censitários da ACF e setores censitários do recorte espacial com incidência de $20 \%$ a $70 \%$ de endereços não residenciais (comerciais, de serviços e industriais)

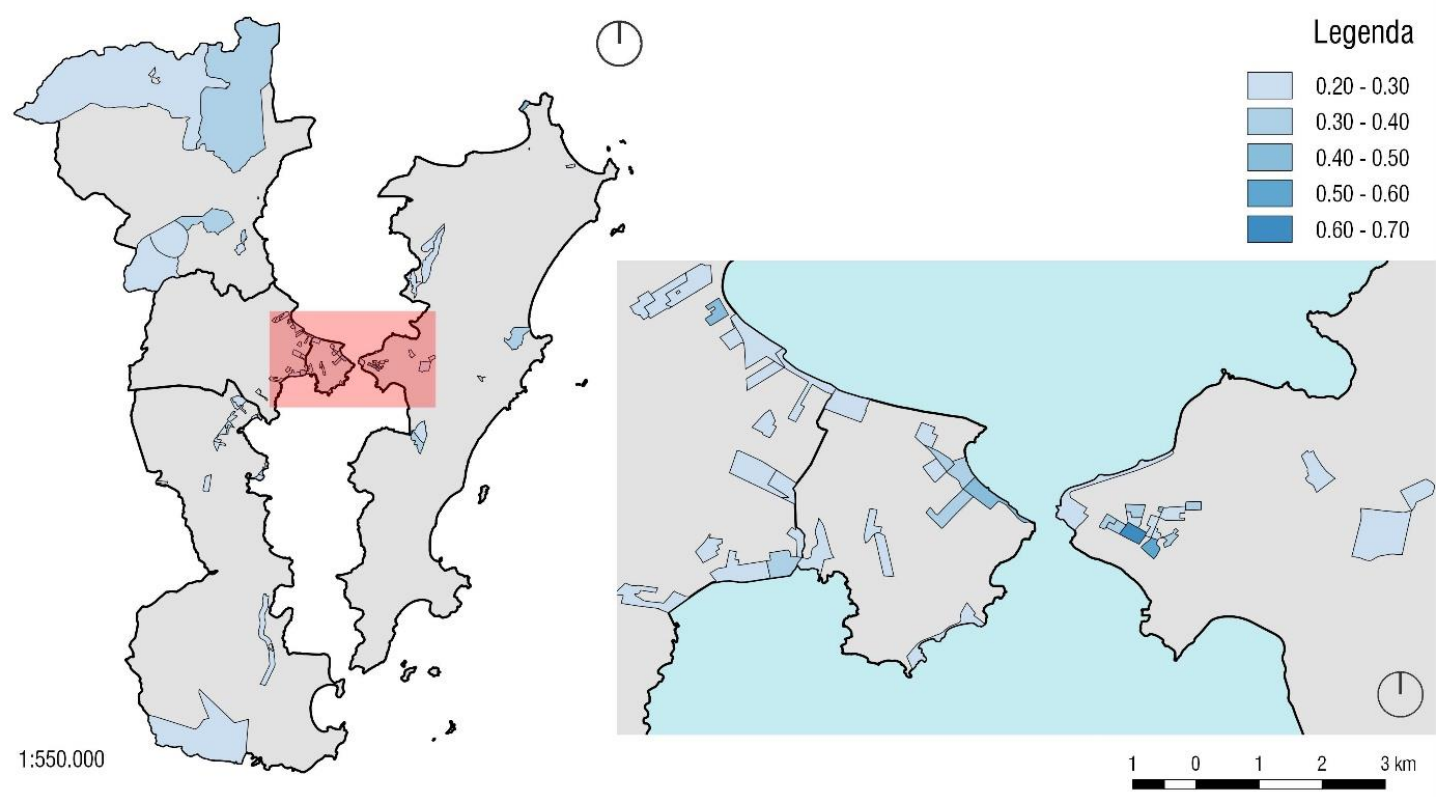

Fonte: Censo Demográfico (INSTITUTO BRASILEIRO DE GEOGRAFIA E ESTATISTICA, 2010). 
Figura 2 - Mapa dos 100 trechos selecionados aleatoriamente pelo software QGIS $(n=100)$ no recorte espacial
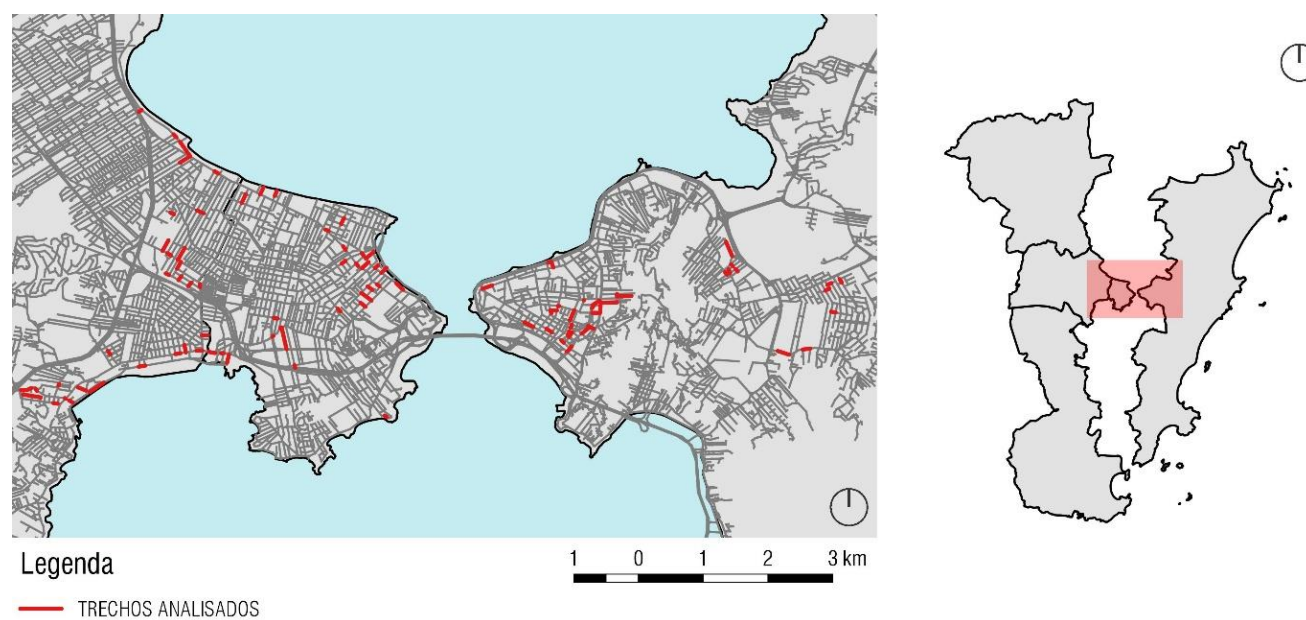

Fonte: INFOARQ (2016).

\section{Levantamento das variáveis independentes}

Levantamento in loco e através das imagens do Google Earth e Street View das características arquitetônicas e de uso do solo de todas as edificações dos trechos selecionados para a amostra, conforme descrito no Quadro 1. A escolha dessas variáveis foi baseada na literatura (JACOBS, 2011; HILLIER; SAHBAZ， 2012; SOHN, 2016), em trabalhos anteriores de um dos autores (SABOYA; BANKI; SANTANA, 2016; VIVAN; SABOYA, 2017) e na operacionalização das hipóteses levantadas neste trabalho.

\section{Agrupamento de dados}

As variáveis levantadas para cada edificação foram agrupadas por trecho através de um script criado especialmente para isso ${ }^{3}$, que gerou medidas normalizadas pelo tamanho do trecho ou pela quantidade de economias, conforme consta do Quadro 2.

\section{Confronto entre as características tipológicas e de uso do solo com a taxa de ocorrências criminais em cada trecho}

Relação entre a variável dependente (taxa de crimes) e os valores das variáveis independentes

${ }^{3} U \mathrm{~m}$ script é um conjunto de funções e de procedimentos escritos em uma linguagem de programação para atingir determinados objetivos. Nesse caso, ele foi escrito em R, uma linguagem própria para análises estatísticas, utilizando funções do pacote dplyr. em cada trecho, através dos gráficos de dispersão, buscando encontrar possíveis relações entre elas.

Em alguns casos, quando havia motivo para suspeitar que uma terceira variável pudesse estar confundindo a relação entre as duas variáveis analisadas nos gráficos, uma regressão múltipla ${ }^{4}$ foi realizada para averiguação.

\section{Resultados e discussões}

Com a produção dos gráficos de dispersão entre variáveis dependentes e independentes, foi possível observar que havia quatro trechos causando distorção nas análises, por possuírem taxas de

crimes bastante elevadas e permanecerem sempre em destaque nos gráficos. Uma análise desses trechos constatou que eram locais atípicos: três deles eram segmentos de rua em uma área segregada e vazia durante grande parte do dia e da noite, enquanto o outro possuía apenas quatro economias. Por introduzirem essa distorção na amostra, foram retirados dos gráficos de dispersão. Sendo assim, todas as análises apresentadas aqui são feitas com os gráficos considerando apenas os 96 trechos restantes.

\section{Número de pavimentos}

Inicialmente, comparamos a taxa de crimes com o número médio de pavimentos de cada trecho (Figura 3).

\footnotetext{
${ }^{4} \mathrm{~A}$ análise de regressão múltipla permite, entre outras coisas, avaliar se a associação de uma variável independente com a dependente mantém-se mesmo quando outras variáveis independentes são consideradas.
} 
Quadro 1 - Variáveis independentes levantadas em campo para cada lote e/ou edificação

\begin{tabular}{|l|l|}
\hline \multicolumn{1}{|c|}{ Variáveis independentes } & \multicolumn{1}{c|}{ Descrição } \\
\hline Edificações em Uso & Edificações que estão sendo utilizadas. \\
\hline Total de Economias & $\begin{array}{l}\text { Quantidade total de economias no trecho (econ.). Cada unidade residencial } \\
\text { ou de comércio, ou de qualquer outra atividade, conta como 1 economia. }\end{array}$ \\
\hline Total de pavimentos & Quantidade total de pavimentos da edificação. \\
\hline Afastamento frontal & $\begin{array}{l}\text { Medida qualitativa que identifica o afastamento frontal das edificações, } \\
\text { diferenciando-os em edificação colada à rua, edificação parcialmente } \\
\text { afastada, edificação posicionada nos fundos do lote e terreno sem edificação. }\end{array}$ \\
\hline Número de janelas & $\begin{array}{l}\text { Quantidade de janelas voltadas para a rua. Caracterizada pela } \\
\text { permeabilidade visual, mas não física. }\end{array}$ \\
\hline Número de portas & $\begin{array}{l}\text { Quantidade de portas voltadas para a rua. Caracterizada pela permeabilidade } \\
\text { física, mas não visual. }\end{array}$ \\
\hline Número de portas-janelas & $\begin{array}{l}\text { Quantidade de portas transparentes, ou seja, que proporcionam } \\
\text { permeabilidade visual e física. }\end{array}$ \\
\hline Visibilidade & $\begin{array}{l}\text { Classificação qualitativa para a interface entre a edificação e via: } \\
\text { baixa visibilidade, média visibilidade ou alta visibilidade. }\end{array}$ \\
\hline $\begin{array}{l}\text { Classificação geral dos } \\
\text { usos }\end{array}$ & $\begin{array}{l}\text { Relação geral dos tipos de usos das edificações: residencial, comercial, } \\
\text { serviços, industrial, institucional, lazer e outros. Essa classificação, assim } \\
\text { como as demais relativas ao uso do solo, foi registrada para cada pavimento } \\
\text { de cada edificação. }\end{array}$ \\
\hline $\begin{array}{l}\text { Classificação conforme a } \\
\text { abrangência/hierarquia do } \\
\text { uso comercial }\end{array}$ & $\begin{array}{l}\text { Classificação dos usos conforme seu raio de influência (local, bairro ou } \\
\text { cidade), considerando o nível de acessibilidade do estabelecimento. }\end{array}$ \\
\hline $\begin{array}{l}\text { Inserção do comércio na } \\
\text { edificação }\end{array}$ & $\begin{array}{l}\text { Comércios em edificações de uso exclusivo, ou seja, aqueles que não } \\
\text { possuem usos residenciais acoplados, e comércios que estão integrados ao } \\
\text { uso residencial. }\end{array}$ \\
\hline
\end{tabular}

\section{Quadro 2 - Descrição dos dados utilizados após o agrupamento por trechos}

\begin{tabular}{|c|c|}
\hline Variáveis agrupadas & Descrição \\
\hline \multicolumn{2}{|r|}{ Variável dependente } \\
\hline Taxa de crimes & $\begin{array}{l}\text { Quantidade total de crimes dividida pelo número total de economias no trecho } \\
\text { (crimes/econ.). Os crimes considerados na pesquisa foram: crimes contra a vida, } \\
\text { violação de domicílio, roubo, furto e drogas. }\end{array}$ \\
\hline \multicolumn{2}{|r|}{ Variáveis independentes } \\
\hline $\begin{array}{l}\text { Densidade linear de } \\
\text { economias }\end{array}$ & Quantidade total de economias por metro linear no trecho (econ./m). \\
\hline $\begin{array}{l}\text { Média do número de } \\
\text { pavimentos }\end{array}$ & Média do número de pavimentos das edificações do trecho (un.). \\
\hline Afastamentos & $\begin{array}{l}\text { Proporção das edificações do trecho posicionadas junto à rua, afastadas em } \\
\text { relação à rua ou posicionadas no fundo do lote }(\%) \text {. }\end{array}$ \\
\hline $\begin{array}{l}\text { Densidade linear de } \\
\text { janelas; de janelas no } \\
\text { térreo; e de aberturas }\end{array}$ & $\begin{array}{l}\text { Quantidade de janelas e portas-janelas/quantidade de janelas e portas-janelas } \\
\text { situadas no térreo ou sobreloja/quantidade de portas, janelas e portas-janelas a } \\
\text { cada } 100 \mathrm{~m} \text { do trecho }(\text { jan. } / 100 \mathrm{~m} \text { ). }\end{array}$ \\
\hline Visibilidade & Proporção de interfaces do lote com baixa ou alta visibilidade $(\%)$. \\
\hline \multirow[t]{2}{*}{ Usos do solo } & $\begin{array}{l}\text { Densidade de usos do solo: quantidade de economias de cada tipo de uso por } \\
\text { metro (econ./m). }\end{array}$ \\
\hline & Proporção de usos do solo: proporção dos cinco tipos de uso no trecho (\%). \\
\hline $\begin{array}{l}\text { Abrangências do uso } \\
\text { comercial }\end{array}$ & $\begin{array}{l}\text { Proporção das abrangências do uso comercial: proporção de usos das escalas } \\
\text { de abrangência local, bairro e cidade no trecho }(\%) \text {. }\end{array}$ \\
\hline $\begin{array}{l}\text { Inserção do uso } \\
\text { comercial na edificação }\end{array}$ & $\begin{array}{l}\text { Proporção das edificações de usos não residenciais isoladas, isto é, não } \\
\text { integradas a usos residenciais, e proporção das edificações de usos não } \\
\text { residenciais integradas a usos residenciais na mesma edificação }(\%) .\end{array}$ \\
\hline
\end{tabular}


Figura 3 - Média de pavimentos $\mathrm{X}$ taxa de crimes

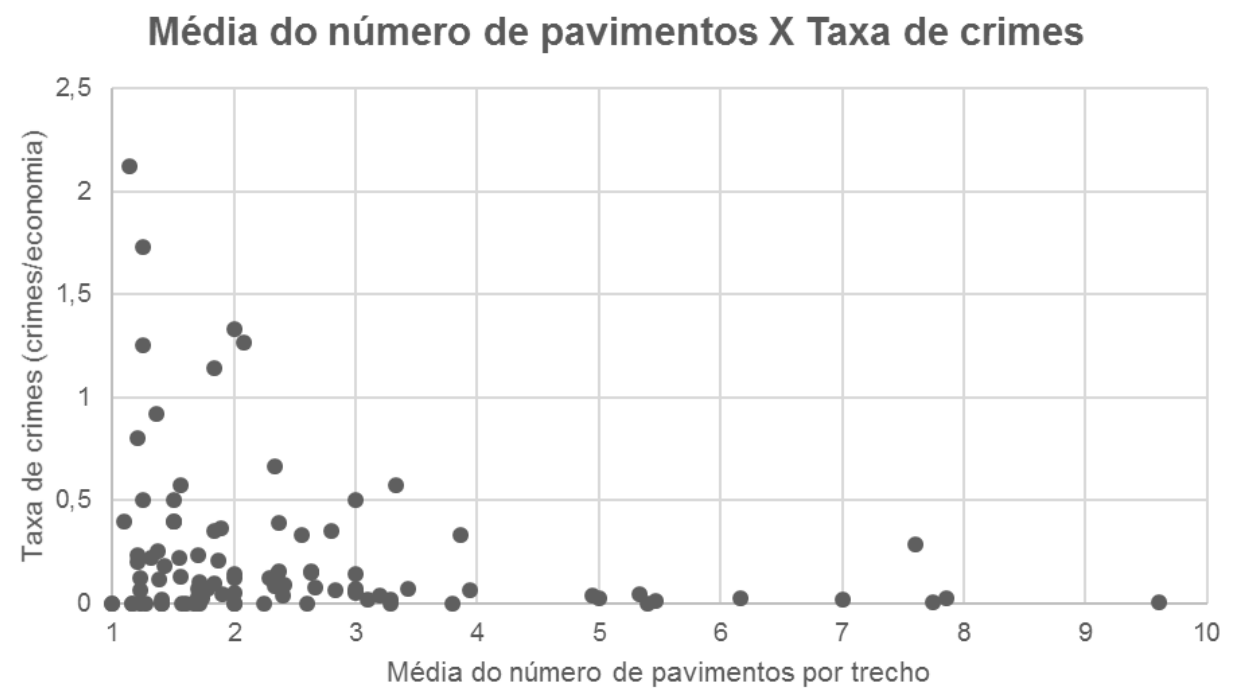

Analisando o gráfico, vemos que edificações mais altas tendem a estar associadas com menores taxas de crimes e que, a partir de cinco pavimentos, independe do número deles para que essa taxa seja consideravelmente baixa $(<0,3)$. Isso talvez seja explicado pelo fato de edificações com menos pavimentos serem mais vulneráveis ao arrombamento devido à maior facilidade de acesso a andares mais baixos. Edificações com maior número de pavimentos podem ser menos vulneráveis devido a algumas características específicas de seus tipos arquitetônicos, tais como presença de portarias e vigilantes, maior distanciamento das unidades em relação à rua e maior quantidade de janelas (consequentemente, mais "olhos para a rua").

\section{Afastamentos}

A variável de afastamentos foi medida através do levantamento qualitativo dos afastamentos das edificações comparando as proporções de cada tipo de afastamento (sem afastamento, com afastamento ou fundos do lote) existente no trecho e sua taxa de crimes. As Figuras 4 e 5 mostram que, em trechos com baixa proporção de edificações no fundo do lote, as taxas de crimes são maiores, assim como naqueles em que há maiores proporções de afastamentos médios. Isso contraria o entendimento de que edificações posicionadas dessa forma tendem a ter sua capacidade de vigilância natural prejudicada pela distância em relação à rua e aponta que afastamentos maiores estariam associados, na verdade, a menores taxas de crimes. A Figura 6, por sua vez, tem um comportamento menos claro, que, entretanto, parece contrariar os dois gráficos anteriores, uma vez que trechos com baixa proporção de edificações coladas à rua apresentaram maiores taxas de crimes. Esse comportamento mais errático ocorre, provavelmente, devido ao fato de que a maioria das edificações sem afastamento são estabelecimentos de uso comercial, e estes, por sua vez, são atratores de criminalidade, conforme mostram tanto a literatura quanto os resultados obtidos neste estudo, descritos adiante. Por outro lado, em edificações não comerciais sem afastamento, é possível que a proximidade com a rua auxilie na vigilância natural.

\section{Densidade de aberturas}

Acerca da densidade das aberturas, a Figura 7 é correspondente a todas as aberturas levantadas, enquanto a Figura 8 considera apenas as janelas, e a Figura 9 representa apenas os valores para as janelas do pavimento térreo.

Com base nesses gráficos, observamos que os trechos com menor densidade de aberturas possuem taxa maior de crimes. Isso acompanha os argumentos de Jacobs (2011) e Newman (1973), que defendiam que, onde há menor visibilidade, há também menor possibilidade de vigilância. Por outro lado, é possível que essa relação seja decorrente, na verdade, do efeito da verticalização sobre a taxa de crimes, uma vez que em áreas mais densas e verticalizadas também há tendência de haver maior densidade de aberturas. De fato, quando considerada a densidade linear de economias através da regressão múltipla, a associação entre a densidade de aberturas e a taxa de crimes tornou-se não significativa. 


\section{Densidade linear de economias}

Com relação à densidade de economias no trecho (Figura 10), constatamos que áreas com baixa densidade são muito mais criminogênicas que as áreas com densidades mais altas, o que corrobora os achados para a quantidade média de pavimentos.

Figura 4 - Proporção de edificações no fundo do lote em cada trecho $X$ taxa de crimes

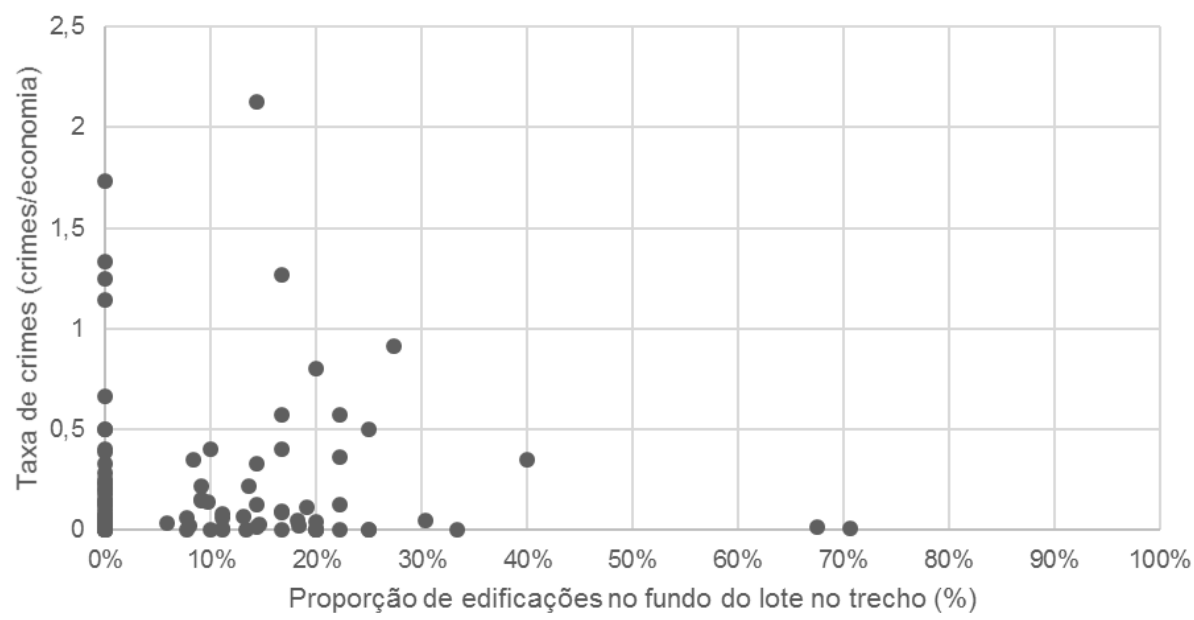

Figura 5 - Proporção de edificações com afastamento médio em cada trecho $X$ taxa de crimes

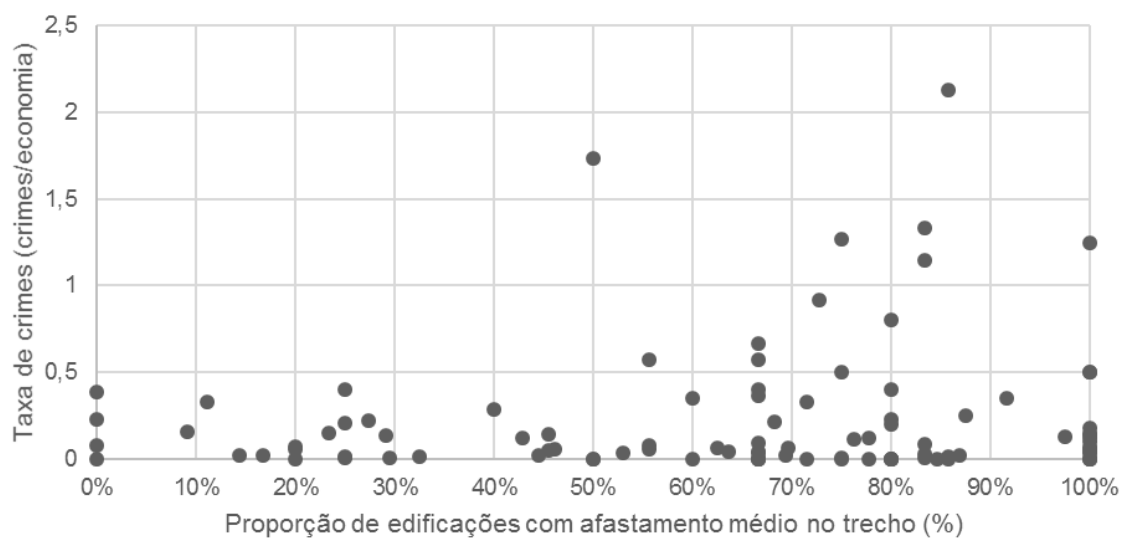

Figura 6 - Proporção de edificações sem afastamento em cada trecho X taxa de crimes

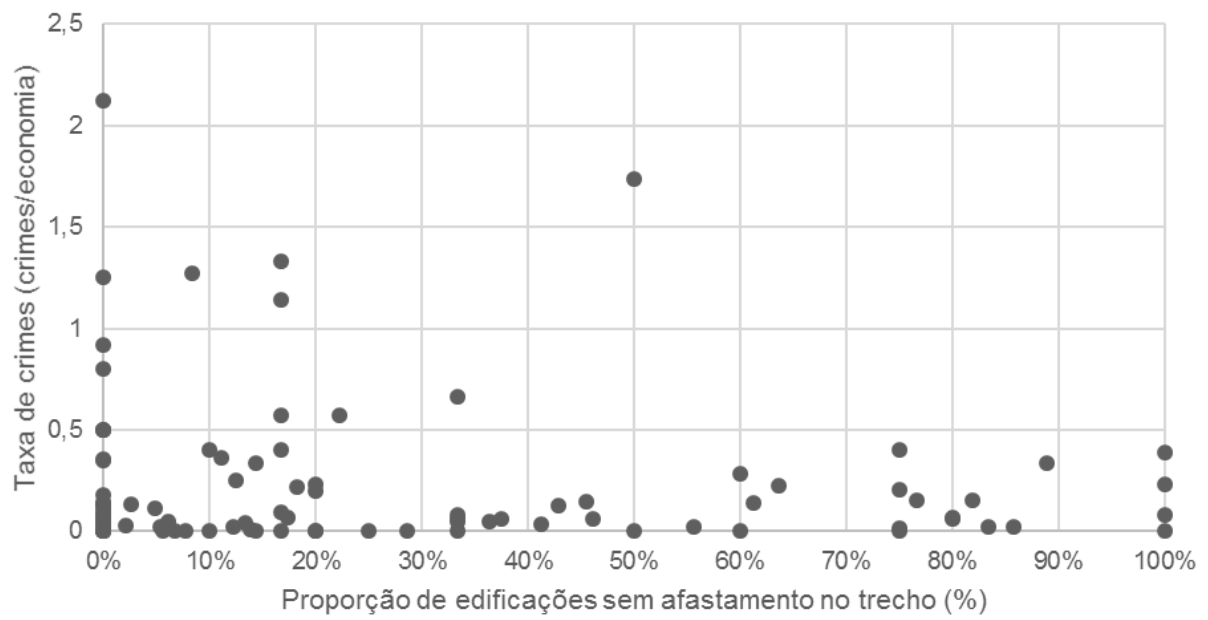


Figura 7 - Densidade linear de aberturas $X$ taxa de crimes

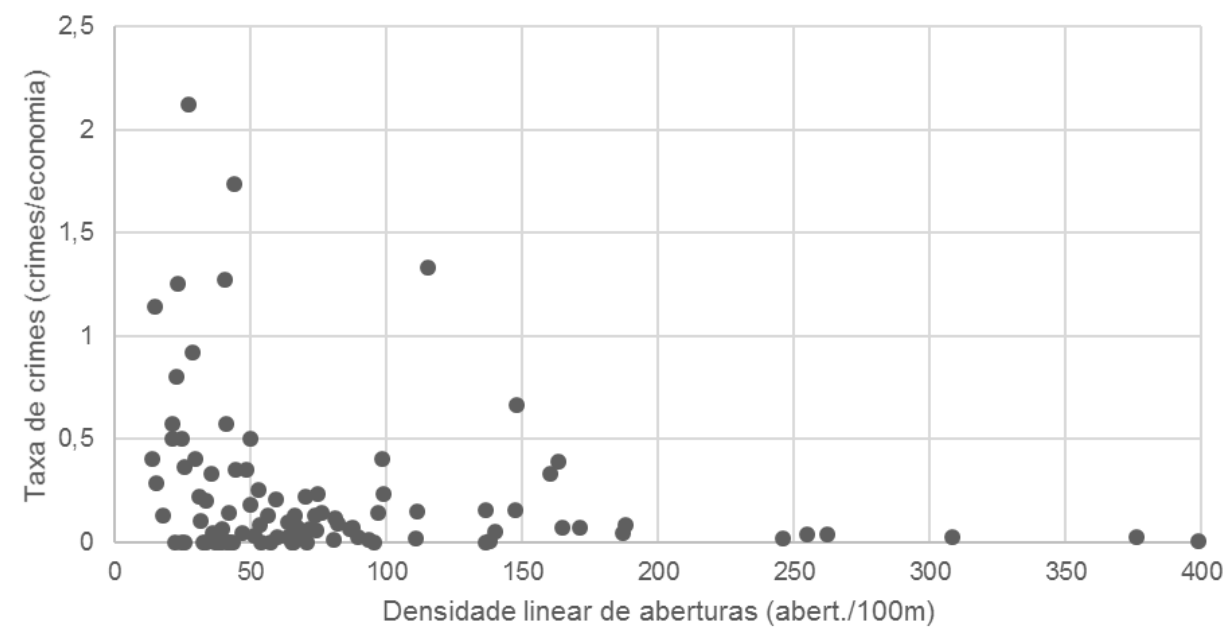

Figura 8 - Densidade linear de janelas $\mathrm{X}$ taxa de crimes

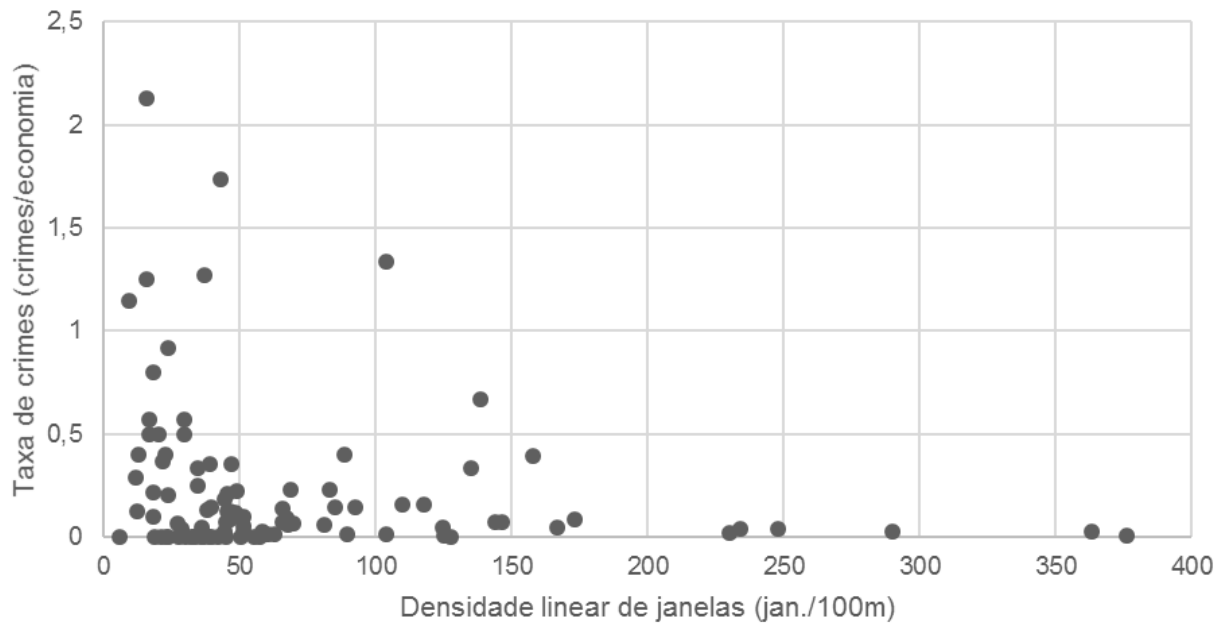

Figura 9 - Densidade linear de janelas no térreo $X$ taxa de crimes

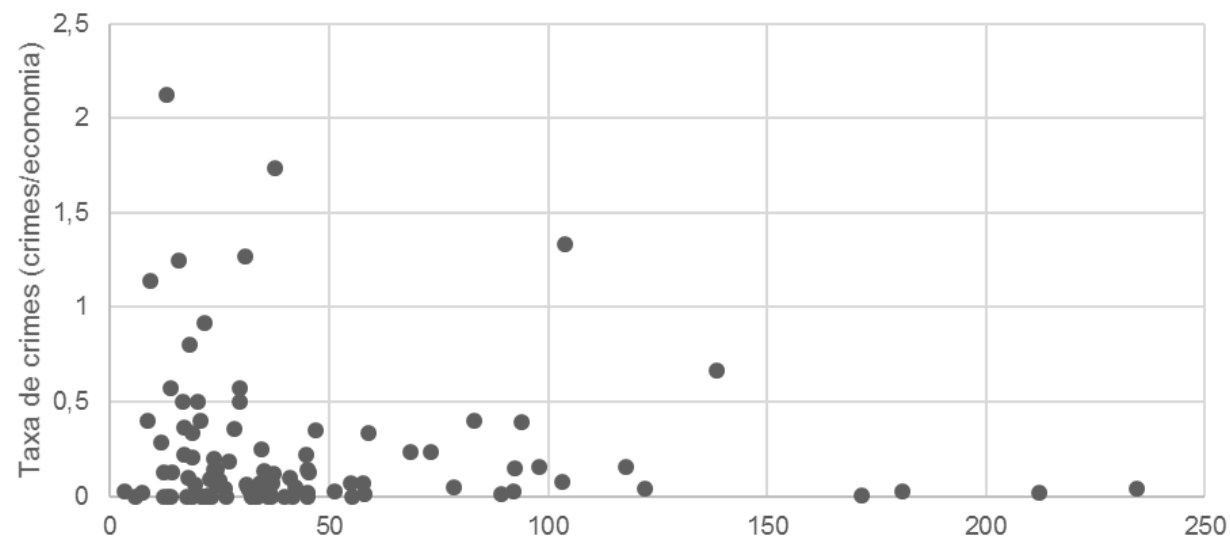

Densidade linear de janelas no térreo (jan. térreo/100m) 
Figura 10 - Densidade linear de economias $X$ taxa de crimes

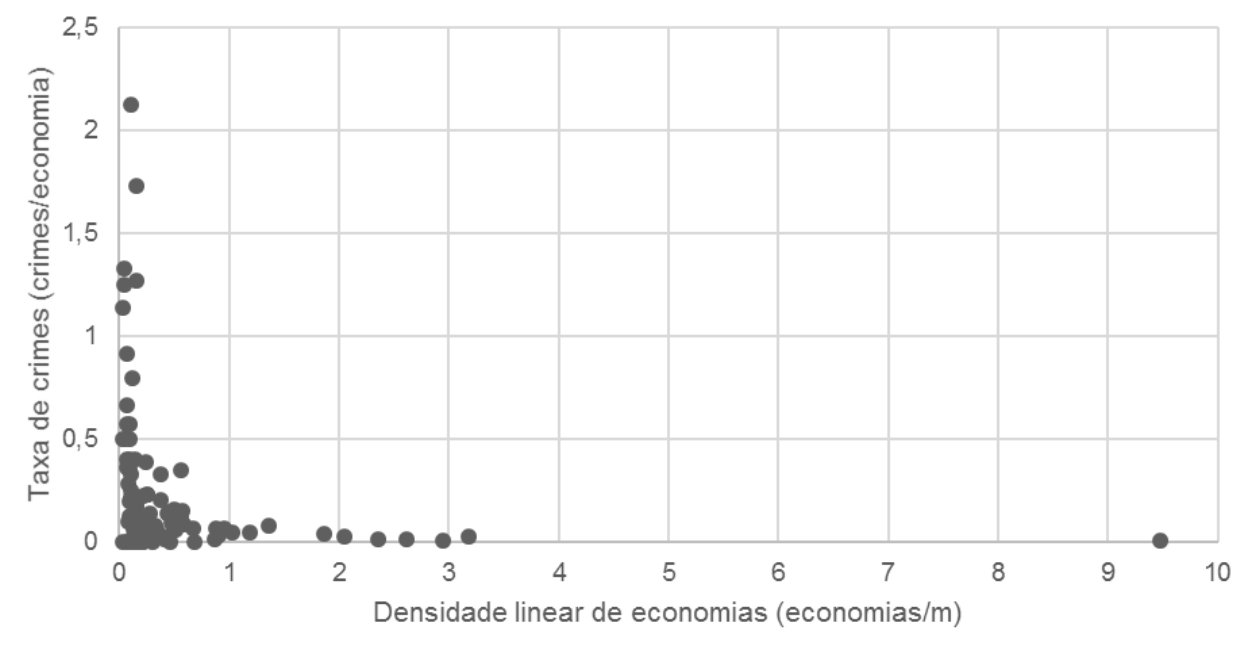

Com esse resultado, pode-se afirmar que essa densidade está associada aos tipos habitacionais, dado que maior densidade em um trecho está comumente associado a edificações mais altas. Portanto, os dados reforçam a noção de que apartamentos são tipos mais seguros que casas. $\mathrm{O}$ mesmo acontece para serviços inseridos em edifícios com alto número de pavimentos, nos quais as economias estão instaladas acima do pavimento térreo. Trata-se de economias mais seguras por serem unidades de mais difícil acesso para os criminosos, não só por seu tipo arquitetônico, como também por alguns fatores externos que essas edificações podem possuir, como portarias e controle eletrônico de segurança.

\section{Uso do solo}

A densidade do uso comercial em cada trecho está ilustrada pelo gráfico de densidade de comércios (Figura 11) e proporção de usos comerciais (Figura 12) e densidade de comércios no térreo (Figura 13). Comparando-os, notamos que o gráfico de densidade indica tendência à diminuição na taxa de crimes à medida que aumenta a densidade de comércios. Para o gráfico de proporções, a dispersão se comporta de maneira diferente, com uma relação menos evidente entre a taxa de crimes e a proporção de uso comercial. A concentração de valores baixos para ambas as variáveis, entretanto, no canto inferior esquerdo do gráfico, sugere que menores proporções de usos comerciais estejam associadas a menores taxas de crimes.

Os serviços, quando analisados de maneira geral, comportam-se de forma diferente dos comércios, sendo menos criminogênicos que estes. Ao comparar os gráficos de densidade (Figuras $14 \mathrm{e}$ 16) e proporção de usos de serviços (Figura 15 e), nota-se que o gráfico de densidade evidencia melhor essa relação positiva entre a existência de usos de serviços para a inibição das ocorrências criminais, enquanto o gráfico de proporções demonstra pouca relação devido a sua maior dispersão.

O uso residencial demonstra ser o menos criminogênico. Ao observar os gráficos, notamos que, independentemente de esse uso estar presente no trecho nos mais diversos pavimentos ou apenas no pavimento térreo, ele pode ser considerado inibidor da criminalidade, uma vez que, quanto maior é sua incidência, menor é a taxa de crimes registrada. $\mathrm{O}$ gráfico de densidade evidencia que, onde a densidade de usos residenciais é maior, a taxa de crimes é menor (Figuras 17 e 19), e o gráfico de proporções (Figura 18) mostra que, quanto maior a proporção de uso residencial no trecho, menor a taxa de ocorrências registrada nele, com apenas um trecho visivelmente discrepante.

A hipótese é a de que a residência tenha tempo de uso e permanência constantes, diferentemente dos usos não residenciais, que funcionam apenas no período comercial. Portanto, acreditamos que essa continuidade na utilização colabore para a vigilância natural e até mesmo para a insegurança do criminoso, uma vez que este não pode saber se está sendo observado e, por isso, optar por não cometer o crime.

Nesse ponto, cabe uma ressalva: como os usos do solo estão normalmente associados à densidade, é possível que esta exerça alguma influência - e cause distorção - nos resultados mostrados nos gráficos. Os resultados da regressão múltipla, entretanto, confirmaram e reforçaram o que os gráficos já haviam sugerido: a proporção de usos comerciais nos trechos mostrou-se consistentemente associada a maiores taxas de 
crimes, mesmo considerando a densidade linear de economias nesses trechos. Já os usos de serviços e residenciais mostraram-se não associados e negativamente associados às taxas de crimes respectivamente.

Figura 11 - Densidade e proporção de uso comercial $X$ taxa de crimes

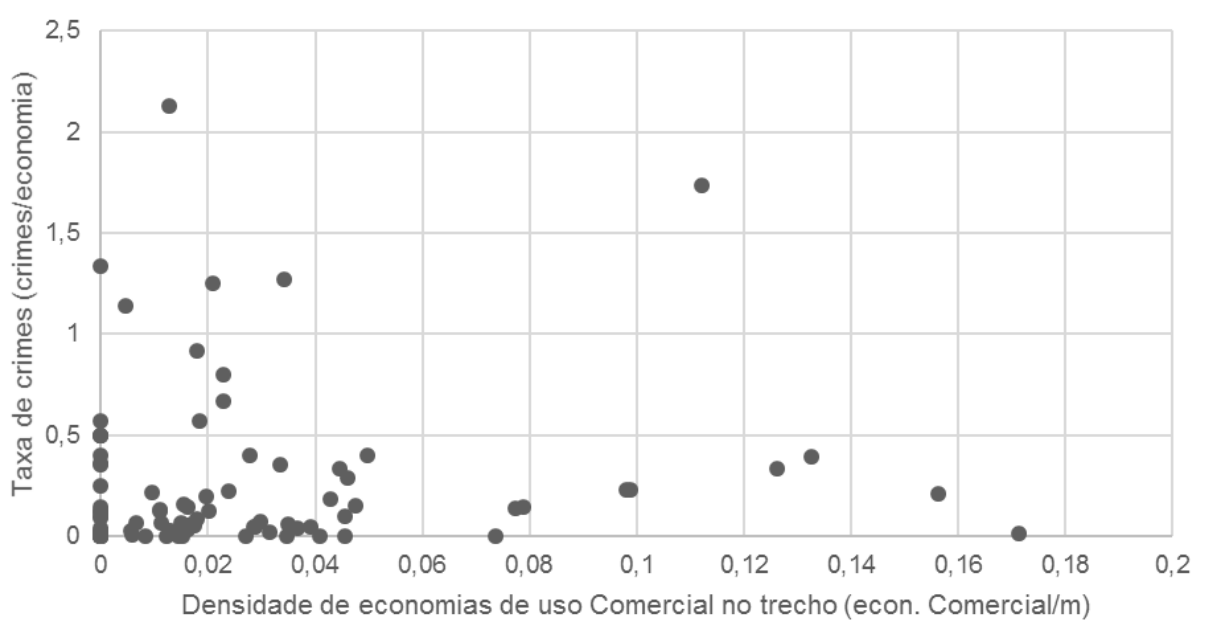

Figura 12 - Proporção de uso comercial X taxa de crimes

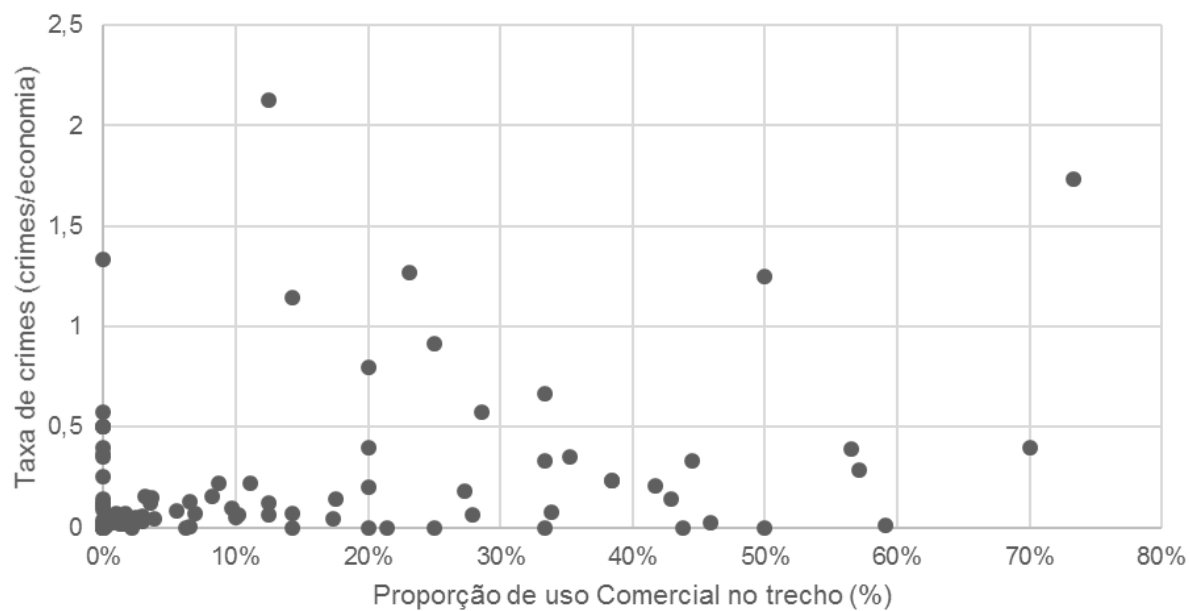

Figura 13 - Densidade de uso comercial no pavimento térreo $X$ taxa de crimes

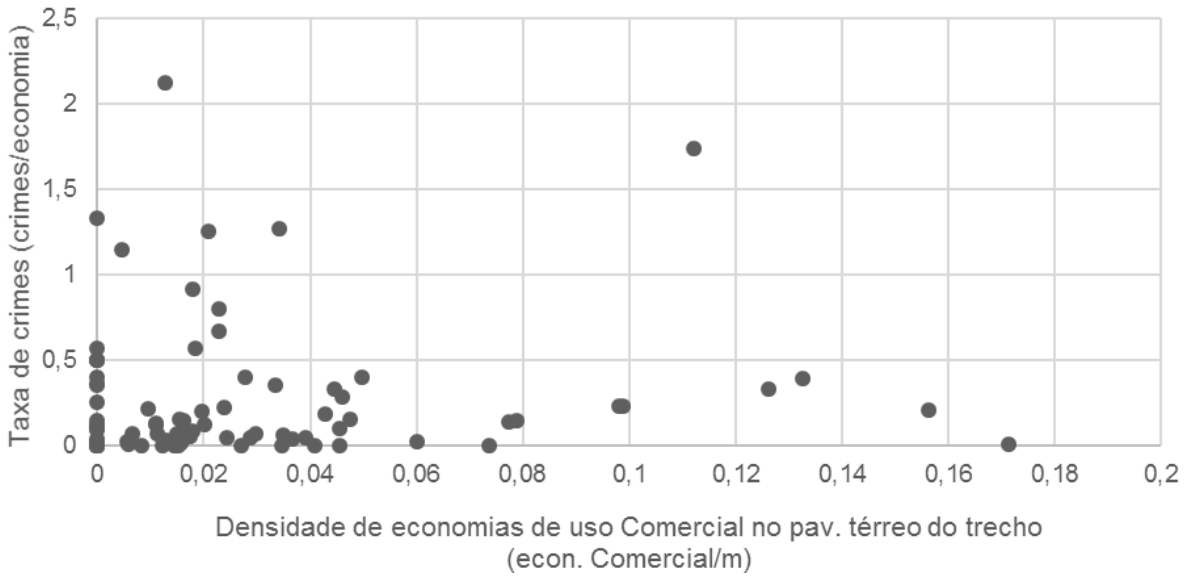


Figura 14 - Densidade do uso de serviços em cada trecho $X$ taxa de crimes

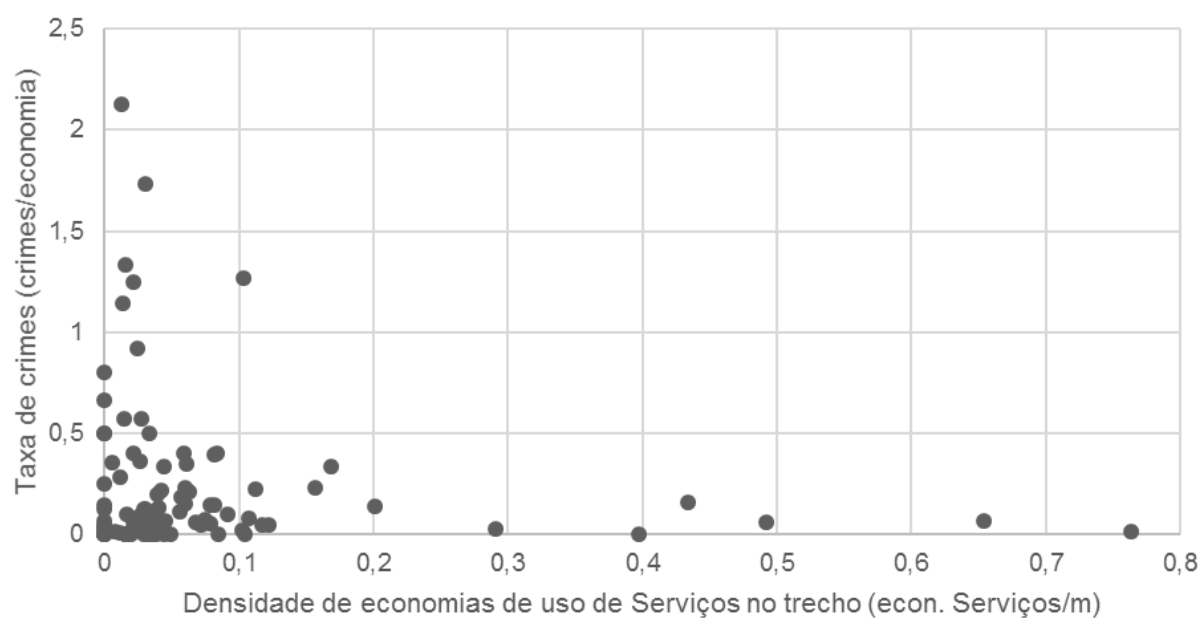

Figura 15 - Proporção de uso de serviços em cada trecho $X$ taxa de crimes

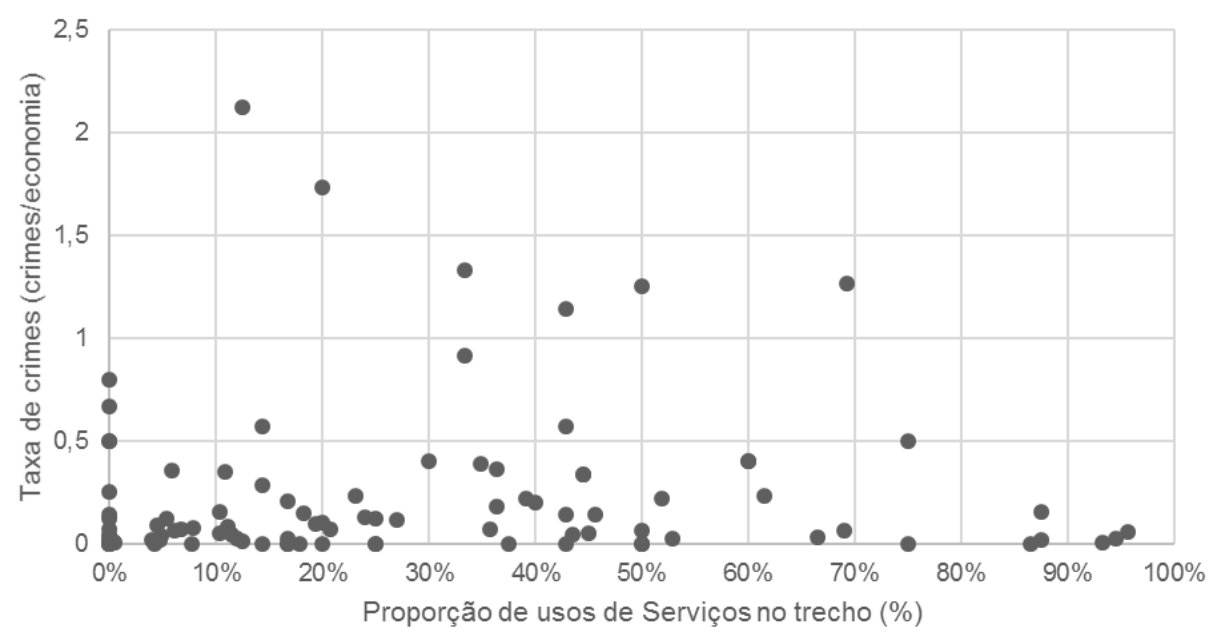

Figura 16 - Densidade de uso de serviços no térreo $X$ taxa de crimes

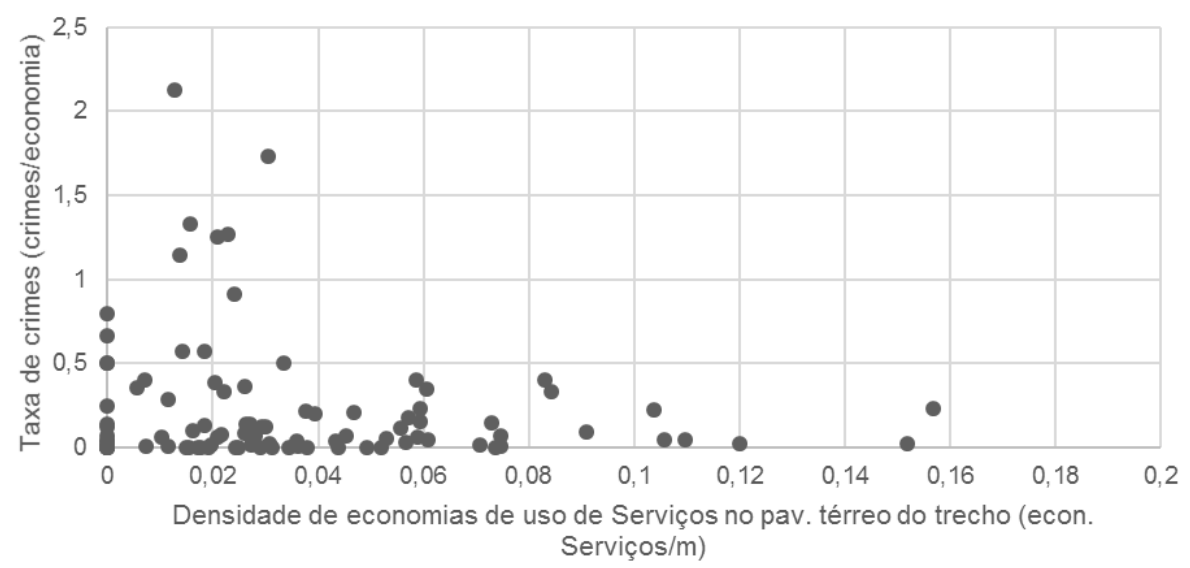


Figura 17 - Densidade e proporção de uso residencial no trecho X taxa de crimes

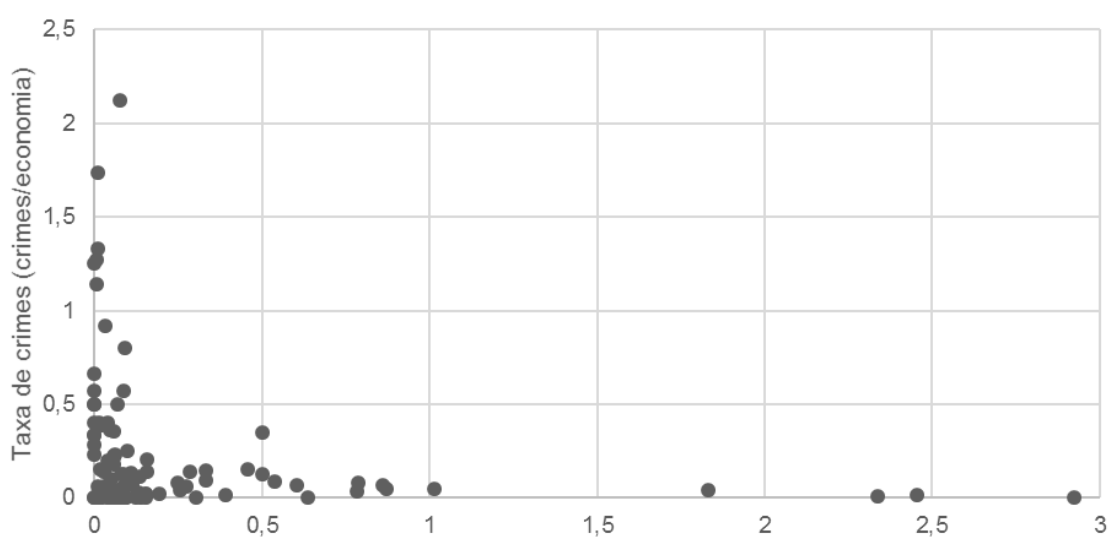

Densidade de economias de uso Residencial no trecho (econ. Residencial/m)

Figura 18 - Proporção de uso residencial no trecho $\mathrm{X}$ taxa de crimes

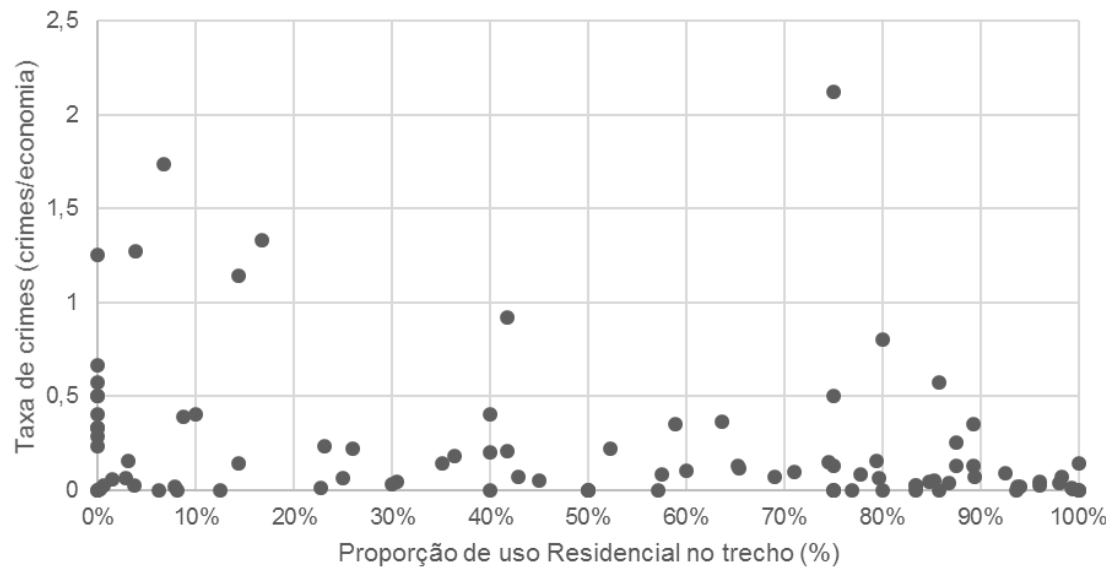

Figura 19 - Densidade de uso residencial no pavimento térreo $X$ taxa de crimes

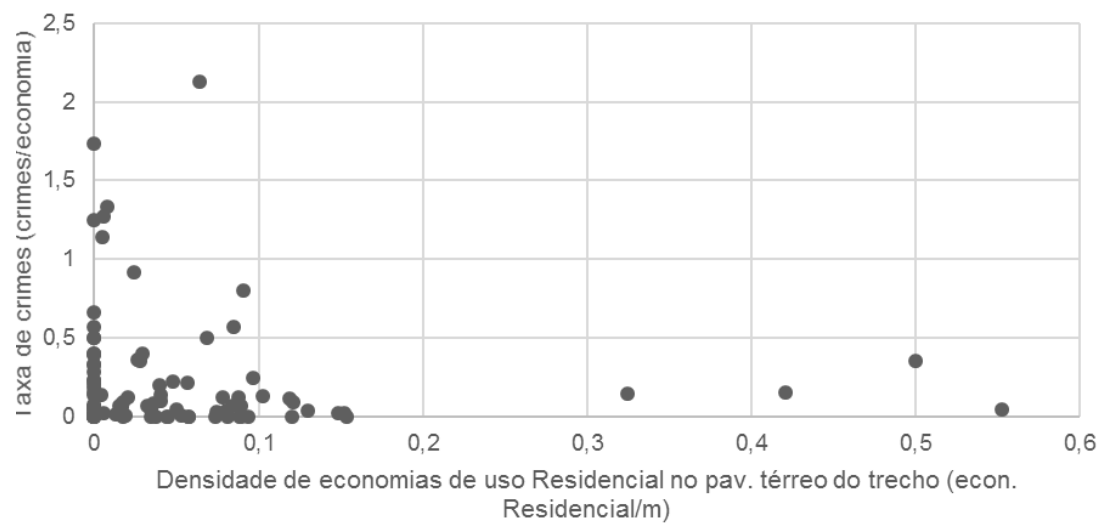

\section{Inserção do uso não residencial na edificação}

A análise da inserção do uso não residencial na edificação foi feita com o intuito de testar a hipótese de que edificações com apenas essa categoria de uso são mais criminogênicas que edificações de uso misto, ou seja, com uso não residencial e residencial.

Nas Figuras 20 e 21 comparou-se a taxa de crimes nos trechos com as proporções de edificações de uso exclusivamente não residencial e edificações de uso misto. 
Figura 20 - Proporção de edificações de uso exclusivamente não residencial $X$ taxa de crimes

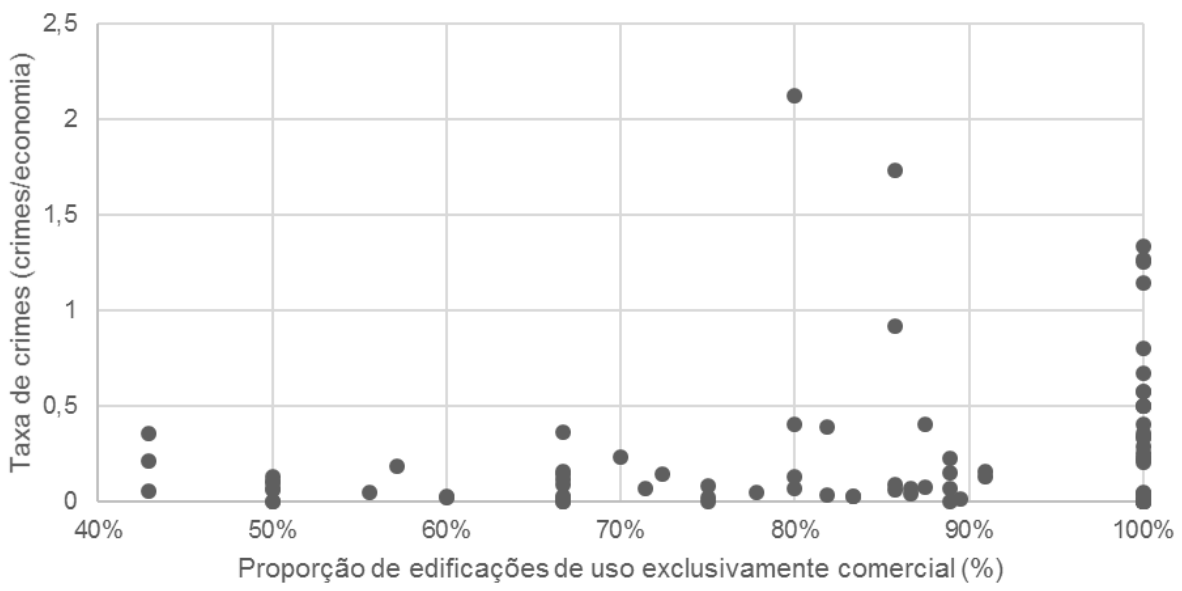

Figura 21 - Proporção de estabelecimentos não residenciais integrados ao uso residencial $X$ taxa de crimes

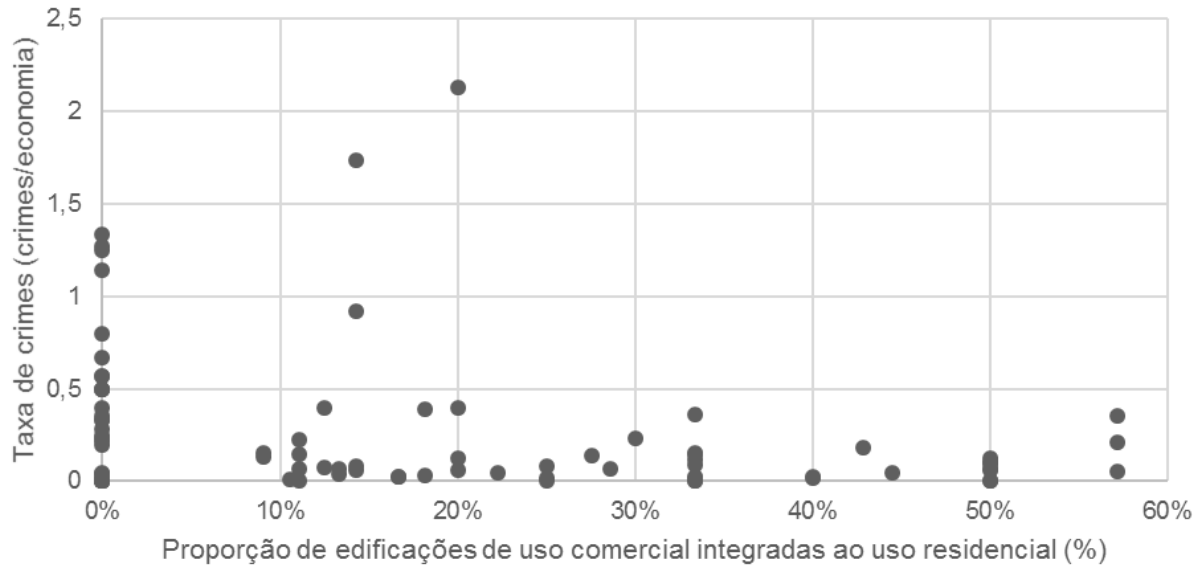

Com base na Figura 20, notamos a tendência em haver uma taxa maior de crimes em trechos com alta proporção de estabelecimentos não residenciais isolados na edificação. Em relação ao uso não residencial integrado ao residencial (Figura 21), observamos o contrário: trechos com maior proporção de edificações com os usos integrados são menos criminogênicos. Esses resultados claramente corroboram os argumentos segundo os quais comércios isolados influenciam na insegurança pelo fato de não haver "olhos da rua" fora do período de funcionamento desses estabelecimentos. Estes se tornam pontos cegos fora dos horários de uso, o que não proporciona a vigilância natural e facilita a ação de criminosos, uma vez que a ausência de guardiões capazes está ligada à oportunidade criminal.

Em conclusão, os dois gráficos confirmam a hipótese levantada neste artigo, que ainda não havia sido explorada em estudos anteriores. Os estabelecimentos comerciais, considerados em termos puramente quantitativos, mostraram-se criminogênicos, mas pode haver situações específicas nas quais eles funcionem de forma diferente, e até mesmo positiva, proporcionando maior diversidade de usos em um único lote, o que reforçaria a segurança, como se acredita ser o caso da inserção desses usos com o uso residencial.

\section{Área de abrangência dos usos comerciais}

A análise de especificidade dos usos comerciais se deu em função da área de abrangência dos estabelecimentos. Ao analisar através dos gráficos de dispersão a proporção de estabelecimentos de uso da cidade, uso de bairro ou uso local, observamos que os dados não são conclusivos.

A Figura 22 demonstra que o uso local não interfere na taxa de criminalidade, tendo em vista que, tanto para trechos com baixa ou alta porcentagem de estabelecimentos comerciais dessa

440 Barause, L.; Saboya, R. T. de 
abrangência, a variação da taxa é bastante similar. Para o gráfico de comércios no nível de bairro (Figura 23), constatamos pequena diminuição da taxa com o aumento da incidência desse tipo de comércio. No entanto, a maioria dos trechos, independentemente da proporção, apresenta taxa de crimes bastante similar. Analisando o gráfico de estabelecimentos comerciais ao nível da cidade (Figura 24), verificamos que há diminuição na taxa de crimes em trechos com proporção maior de comércios com essa abrangência de uso, o que contraria a hipótese levantada inicialmente. Entretanto, a regressão múltipla, considerando tanto a escala do uso não residencial quanto a densidade linear de economias, mostrou que esta última escala está positivamente associada às taxas de crimes, ou seja, quando aumenta a proporção da primeira, também tende a aumentar a proporção da segunda. Isso se explica porque, como vimos, essa densidade está associada a menos crimes e também, supostamente, à maior quantidade de usos em escala da cidade. Quando seu efeito é neutralizado pela regressão múltipla, o efeito criminogênico dos usos não residenciais na escala da cidade fica mais evidente. Para os usos em escala local e de bairro, por outro lado, mais uma vez não foram observados efeitos sobre as taxas de crimes.

Figura 22 - Proporção de comércios de uso local $\mathrm{X}$ taxa de crimes

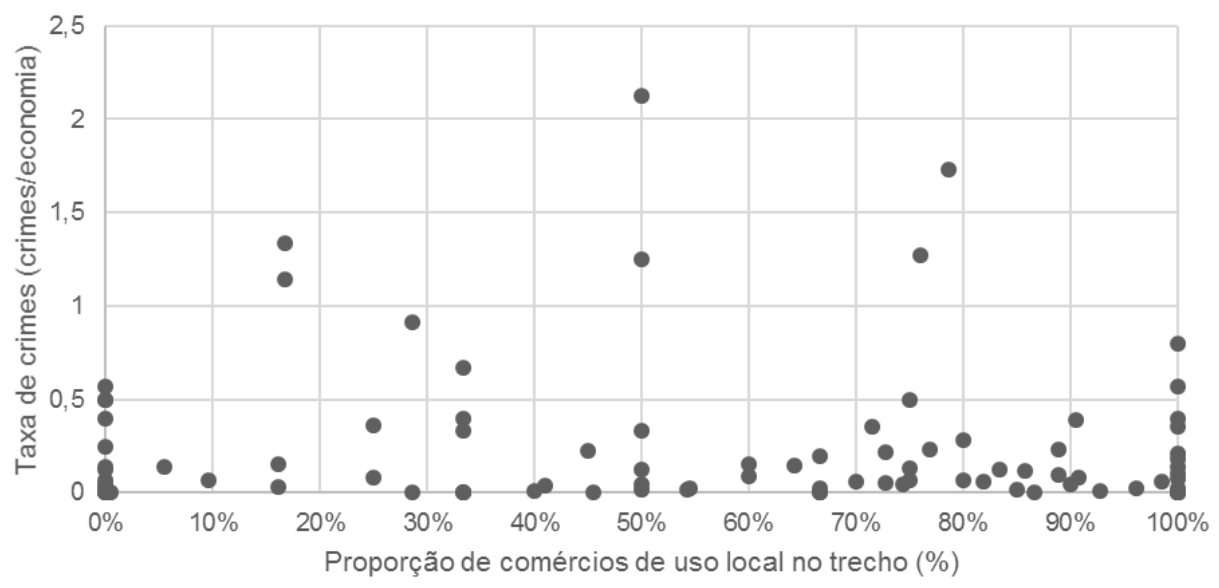

Figura 23 - Proporção de comércios de uso de bairro $X$ taxa de crimes

Proporção de comércios de uso de bairro $X$ Taxa de crimes

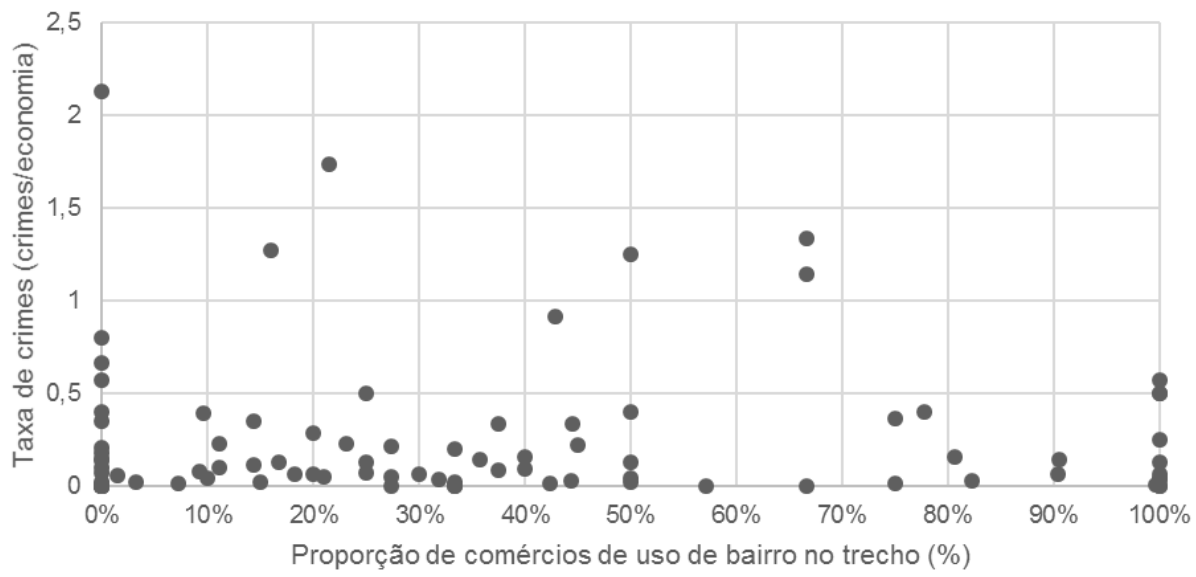


Figura 24 - Proporção de comércios de uso da cidade $X$ taxa de crimes

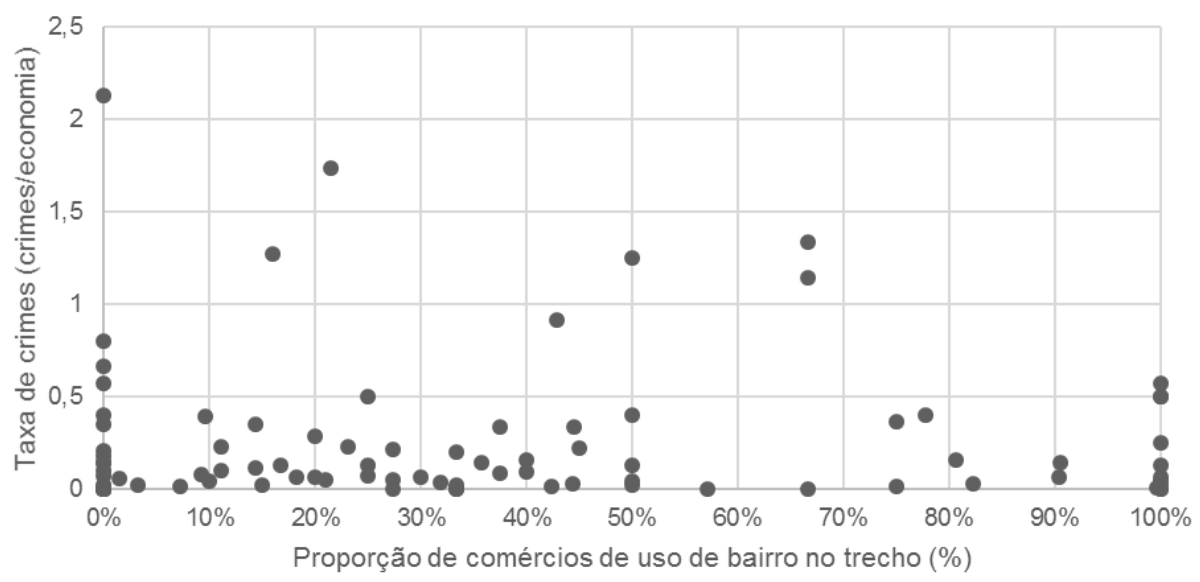

\section{Conclusões}

As análises realizadas conseguiram jogar luz sobre vários aspectos da relação entre a forma edificada e a ocorrência de crimes. Um primeiro aspecto importante é constatar a relação tanto do número de pavimentos como da densidade de economias com baixas taxas de crime. Edificações com mais andares mostram-se mais seguras, o que pode estar relacionado ao distanciamento que as unidades habitacionais têm com a rua, o que dificulta o acesso a elas, tornando-as mais seguras. A forma arquitetônica dessas edificações, com mais pavimentos, também é um ponto positivo nesse sentido, pois normalmente implica menor número de interfaces com a rua, principalmente no pavimento térreo, o que dificulta o acesso e facilita a vigilância.

É importante ressaltar ainda que a densidade de usos também está ligada à densidade de pessoas, que auxilia na vigilância natural do espaço, mesmo que alguns autores, como Acioly e Davidson (1998), acreditem que a falta de segurança e a criminalidade estão atreladas à grande densidade do espaço. Os resultados encontrados nesta pesquisa, ao contrário, vão ao encontro do estudo de Hillier e Sahbaz (2012), que afirmam que a densidade, muitas vezes responsabilizada pelo aumento da criminalidade, está, na verdade, associada à maior segurança. Eles atestam que apartamentos mostram-se mais seguros que casas e que estas, se forem locadas contínuas umas às outras (em fita), podem tornar-se menos inseguras. Para eles, o que torna a edificação mais vulnerável é o número de faces expostas.

É essencial reconhecer, portanto, que não bastam considerações apenas quantitativas sobre a densidade, mas também sobre a forma que essa densidade assume no espaço, uma vez que densidades igualmente altas podem ser espacializadas de maneiras muito diferentes.

Os resultados deste trabalho permitem avançar nessa direção. As análises apontam que usos não residenciais isolados no lote mostram-se mais criminogênicos que aqueles integrados aos usos residenciais na mesma edificação. Usos não residenciais têm horários limitados de funcionamento, os quais limitam também a possibilidade de vigilância. Portanto, não importa quão boa seja a interface e a visibilidade de um lote e seu edifício com a rua, ou quão fácil seja a possibilidade de vigilância, se não há quem os vigie. Essa interface, embora possa aparentar adequada para manter a segurança, sem um vigilante pode tornar-se um bom alvo para o criminoso. Esse resultado traz um novo entendimento e complementa a literatura existente, pois diversos estudos empíricos constataram que espaços de uso misto são mais positivos para a segurança do que zonas estritamente comerciais, porém nenhum deles destacou a importância de combinar esses usos na mesma edificação.

Portanto, a densidade precisa estar associada a configurações e combinações de forma arquitetônica e uso do solo que sejam favoráveis ao surgimento de vitalidade urbana e à vigilância natural. Densidades alcançadas através de torres isoladas, por exemplo, podem ser prejudiciais para a vitalidade e implicar longas interfaces cegas. Além disso, essas torres não são adequadas para usos comerciais integrados, forçando-os a ser implementados em edificações isoladas, e grandes alturas dificultam a visibilidade do morador e o distanciam do espaço público, o que impossibilita a vigilância deste.

Para a abrangência de usos não residenciais, os resultados obtidos são importantes porque ajudam a entender melhor quais tipos de comércios e serviços tendem a ser mais criminogênicos e quais 
não contribuem necessariamente para o aumento da insegurança. Ao notar que os usos locais e de bairro demonstram ser menos criminogênicos que usos na escala da cidade, acreditamos na importância de investir em bairros de uso misto, com alta diversidade de uso do solo, contemplando comércios e serviços prioritariamente destinados aos moradores da região. Esses usos, quando vinculados ao uso residencial, têm alto potencial para gerar sensação de segurança aos usuários, desde que a forma arquitetônica em que estão dispostos seja levada em consideração. É importante que as edificações mesclem os usos não residenciais com os residenciais a fim de possuir vigilância natural em período integral, de forma que as residências supram a falta da vigilância dos estabelecimentos comerciais no período em que estes estão fora de funcionamento.

Durante o processo de coleta dos dados algumas dificuldades foram encontradas. Os dados obtidos, apesar de serem bastante amplos e representarem um avanço na disponibilidade desse tipo de informação considerando o contexto brasileiro, não são completos e ainda geram algumas dificuldades em identificar se os crimes realmente ocorreram e quais foram os alvos: pedestres, residências ou estabelecimentos não residenciais. Essas informações poderiam ser úteis para identificar a influência do uso comercial exclusivamente no crime contra a residência, examinando as diferenças entre os tipos de crimes. No entanto, essa lacuna pode ser preenchida futuramente por outros estudos.

Com base no que foi encontrado até o momento, vemos que ainda há muito a ser discutido e aprimorado em relação aos mecanismos que norteiam o uso e ocupação do solo, tendo em vista que, em muitos casos, os tipos arquitetônicos incentivados por nossa legislação territorial são também os que estão mais ligados às ocorrências criminais, como é o caso, por exemplo, de zonas de usos exclusivos e com baixíssima densidade. A necessidade de usos mistos na mesma edificação, normalmente ignorada por nossa legislação urbanística, ganha, a partir desses resultados, uma base empírica que lhe confere uma justificativa mais forte. É importante uma revisão dos instrumentos existentes em busca de recursos mais aprimorados em relação à forma arquitetônica e usos do solo pensados com o propósito de aliar segurança e vitalidade na cidade.

\section{Referências}

ACIOLY, C.; DAVIDSON, F. Densidade

Urbana: um instrumento de planejamento e gestão urbana. Rio de Janeiro: Mauad, 1998.
ALEXANDER, C. et al. A Pattern Language: towns, buildings, construction. New York: Oxford University Press, 1977.

ANDERSON, J. et al. Reducing Crime by Shaping the Built Environment With Zoning: an empirical study of Los Angeles. University of Pennsylvania Law Review, v. 161, n. 3, p. 699-756, 2013.

BLOCK, R. L.; BLOCK, C. R. Space, Place and Crime: hot spots areas and hot places of liquorrelated crime. In: ECK, J.; WEISBURD, D. (Eds.). Crime and Place. Monsey: Willow Tree Press, 1995.

BRANTINGHAM, P. L.; BRANTINGHAM, P. J. Criminality of Place. European Journal of Criminal Policy and Research, v. 3, n. 3, p. 1-26, 1995.

COHEN, L. E.; FELSON, M. Social Change and crime RATE Trends: a routine activity approach. American Sociological Review, 1979.

D’ANTONA, Á. de O.; DAGNINO, R. S.; BUENO, M. do C. D. Geotecnologias e Gestão de Políticas Públicas: uso de dados demográficos. In: BAENINGER, R. (Org.). População e Cidades: subsídios para o planejamento e para as políticas sociais. Brasília: Unfpa, 2010.

ENDLICH, A. M.; FERNANDES, P. H. C. Aumento da Violência em Pequenas Cidades, Sentimento de Insegurança e Controle Social. In: COLÓQUIO INTERNACIONAL DE GEOCRÍTICA, 13., Barcelona, 2014. Anais... Barcelona: Geocrítica, 2014.

FELSON, M. Understanding the Crime Event: routine activity approach. In: WORTLEY, R.; MAZEROLLE, L. (Eds.). Environmental Criminology and Crime Analysis.Cullompton: Willan Publishing, 2008.

GEHL, J. Life Between Buildings: using public space. 6. ed. Washington: Island Press, 2011.

HILLIER, B.; SAHBAZ, O. Safety in Numbers: high-resolution analysis of crime in street networks. In: CECCATO, V. (Ed.). The Urban Fabric of Crime and Fear.Dordrecht: Springer Netherlands, 2012.

INFOARQ. Grupo de Pesquisa Urbanidades. Base de Dados em Shapefile:mapa de segmentos da Grande Florianópolis. Universidade Federal de Santa Catarina, InfoARQ, 2016.

INSTITUTO BRASILEIRO DE GEOGRAFIA E ESTATÍSTICA. Censo Demográfico 2010:

Cadastro Nacional de Endereços para Fins Estatísticos (CNEFE). 2010. Disponível em: <http://cod.ibge.gov.br/3601>. Acesso em: 23 ago. 2016. 
INSTITUTO BRASILEIRO DE GEOGRAFIA E ESTATÍSTICA. Indicadores de

Desenvolvimento Sustentável: dimensão social: segurança. 2004. Disponível em:

<http://www.ibge.gov.br/home/geociencias/recurs osnaturais/ids/seguranca.pdf $>$. Acesso em: 10 set. 2016.

\section{INSTITUTO DE PESQUISA ECONÔMICA}

APLICADA. Criminalidade Avança Pelo Interior. Revista de Informações e Debates do Instituto de Pesquisa Econômica Aplicada,v. 52, n. 6, p. $1-2,2009$.

JACOBS, J. Morte e Vida de Grandes Cidades. 3. ed. São Paulo: Martins Fontes, 2011.

KINNEY, J. B. et al. Crime Attractors, Generators and Detractors: Land Use and Urban Crime Opportunities. Built Environment, v. 34, n. 1, p. 62-74, 2008.

NEWBURN, T. Criminology. $2^{\text {nd }}$. ed. Abingdon: Oxon; New York, NY: Routledge, 2012.

NEWMAN, O. Defensible Space: crime prevention through urban desing. New York: Macmillan, 1973.

PERKINS, D. D. et al. The Physical Environment of Street Crime: defensible space, territoriality and incivilities. Journal of Environmental Psychology, v. 13, n. 1, p. 29-49, 1993.
SABOYA, R. T. de; BANKI, G. H.; SANTANA, J. M. A. de.Uso do Solo, Visibilidade e Ocorrência de Crimes:um estudo de caso em Florianópolis, Santa Catarina. Oculum Ensaios, v. 13, n. 2, 2016.

SHECAIRA, S. S. Criminologia. São Paulo: Revista dos Tribunais, 2004.

SOHN, D.-W. Do All Commercial Land Uses Deteriorate Neighborhood Safety?: examining the relationship between commercial land-use mix and residential burglary.Habitat International,v. 55, p. 148-158, 2016.

VIVAN, M.; SABOYA, R. T. de. Arquitetura, Espaço Urbano e Criminalidade: efeitos da visibilidade na distribuição da ocorrência de crimes. In: NETTO, V. et al. (Orgs.). Efeitos da Arquitetura: os impactos da urbanização contemporânea no Brasil. Brasília: FRBH, 2017.

WAISELFISZ, J. J. Mapa da Violência 2016: homicídios por armas de fogo no Brasil. Rio de Janeiro: FLACSO/CEBELA, 2015.

\section{Agradecimento}

Esta pesquisa contou com o apoio da Coordenação de Aperfeiçoamento de Pessoal de Nível Superior (Capes).

\section{Letícia Barause}

Departamento de Arquitetura e Urbanismo | Universidade Federal de Santa Catarina | Campus Universitário Reitor João David Ferreira Lima, Trindade | Florianópolis - SC - Brasil | CEP 88040-970 | Tel.: (48) 3721-4860 | E-mail: leticiabarause@hotmail.com

Renato Tibiriçá de Saboya

Departamento de Arquitetura e Urbanismo | Universidade Federal de Santa Catarina | E-mail: rtsaboya@gmail.com

Revista Ambiente Construído

Associação Nacional de Tecnologia do Ambiente Construído

Av. Osvaldo Aranha, $99-3^{\circ}$ andar, Centro

Porto Alegre - RS - Brasil CEP $90035-190$

Telefone: +55 (51) 3308-4084

Fax: +55 (51) 3308-4054

www.seer.ufrgs.br/ambienteconstruido

E-mail: ambienteconstruido@ufrgs.br

\section{(i)}

This is an open-access article distributed under the terms of the Creative Commons Attribution License.

444 Barause, L.; Saboya, R. T. de 